\title{
NOTE
}

\section{Relative swimming speeds in reef fish larvae}

\author{
David R. Bellwood*, Rebecca Fisher
}

Department of Marine Biology James Cook University, Townsville, Queensland 4811, Australia

\begin{abstract}
In most organisms relative locomotor speed (body lengths per second $\left[\mathrm{bls}^{-1}\right]$ ) is inversely proportional to body size. The ability of late stage reef fish larvae to achieve swimming speeds of over $40 \mathrm{bls}^{-1}$ is consistent with this general scaling relationship. However, this relationship does not extend to smaller larvae which are not fully developed. Maximum critical swimming speeds appear to be limited by both developmental stage and size. At $7 \mathrm{~mm}$ total length when settling, the unusually small larvae of anemonefishes are able to sustain speeds of $49 \mathrm{bls}^{-1}$. This probably approaches the maximum limit for sustained aquatic vertebrate locomotion.
\end{abstract}

KEY WORDS: Swimming $\cdot$ Coral reef fish $\cdot$ Larvae $\cdot$ Development $\cdot$ Settlement

Resale or republication not permitted without written consent of the publisher

Although smaller animals move more slowly than larger animals (Alexander 1982), their relative speed in body lengths per second $\left(\mathrm{bls}^{-1}\right)$ is almost invariably higher. In terrestrial systems, vertebrate offspring are relatively large at the onset of independent locomotion. Only in aquatic vertebrates can we see diminutive individuals capable of independent locomotion. While reef fish larvae have been assumed to be poorly developed and capable of only limited movement (Williams et al. 1984, Roberts 1997), recent works have highlighted the potential impact of active movement in shaping dispersal patterns and settlement success (Armsworth 2000, Cowen et al. 2000, Armsworth et al. in press). These latter studies incorporate information on the remarkable swimming performance of late stage larvae of coral reef fishes, with long-term sustained swimming bouts covering the equivalent of up to $140 \mathrm{~km}$, and short-term sustained swimming speeds of up to $65 \mathrm{~cm} \mathrm{~s}^{-1}$ (Stobutzki \& Bellwood 1994, 1997, Leis \& Carson-Ewart 1997). These swimming speeds appear to be quite extraordinary; however, they have not yet been compared to other fishes in terms of their relative swimming speeds.

*E-mail: david.bellwood@jcu.edu.au
Studies investigating the swimming abilities of tropical reef fish larvae have concentrated almost entirely on the oldest larval stages. This reflects the limitations of the light traps which are commonly used to catch larvae for behavioural experiments (Choat et al. 1993). These larvae are at a relatively advanced state of development. We set out to determine: (1) whether the swimming ability exhibited by late pelagic stage individuals is exceptional or simply a reflection of the small size of reef fish larvae, and (2) how the relative swimming speeds of larvae are influenced by developmental stage. We selected 3 study species that varied in size at settlement and rate of development, and used captive breeding techniques to conduct swimming trials throughout the developmental period of each species (following Fisher et al. 2000).

Materials and methods. Three species of reef fish were examined: Pomacentrus amboinensis (Pomacentridae, Pomacentrinae), Amphiprion melanopus (Pomacentridae, Amphiprioninae) and Sphaeramia nematoptera (Apogonidae). These species differ considerably in their age and size at settlement. P. amboinensis and $S$. nematoptera have long larval durations of $\sim 20$ and $24 \mathrm{~d}$ and settle at approximately 15 and $13 \mathrm{~mm}$ total length (TL), respectively. In contrast $A$. melanopus has a very short larval duration of approximately $9 \mathrm{~d}$ and settles at $\sim 7$ to $8 \mathrm{~mm}$ TL. Rearing methods follow Job \& Bellwood (2000). Swimming experiments were carried out throughout the larval period of each species using swimming flumes following Stobutzki \& Bellwood (1997) and Fisher et al. (2000). Three batches of young from each species were used in the swimming trials. At each experimental age, 8 to 12 fish were taken from each batch (without replacement) and the fastest individual swimming speed recorded (as $U_{\text {criti }}$ see below). Maxima rather than means were used to provide estimates of maximum swimming speeds. If larvae are exceptional swimmers, for their size, then these values will reveal the full extent of their unusual 
abilities. Fish were stimulated to swim based on positive rheotaxis and phototaxis.

Burst, cruising and critical swimming speeds have all been used to measure the swimming abilities of fish larvae (Miller et al. 1988, Stobutzki \& Bellwood 1994). However, comparisons between studies are difficult because the values obtained may vary widely depending on the methods employed. Short duration observations give higher estimates of relative swimming speeds. To facilitate comparisons between published records using different taxa and developmental ages, swimming speeds were compared based solely on estimates of critical swimming speeds $\left(U_{\text {crit }}\right)$. $U_{\text {crit }}$ is an intermediate measure of speed, slower than burst speed, but faster than cruising speeds, and it provides a maximum performance measure of short-term sustained swimming. The flow rate against which the fish is swimming is increased incrementally at set time intervals. In the present study, larvae were subjected to incremental increases in flow rates equivalent to approximately 3 body lengths (BL) every 2 min until they could no longer maintain position for the full $2 \mathrm{~min}$. The equation used to calculate $U_{\text {crit }}$ followed Brett (1964): $U_{\text {crit }}=U+\left(t / t_{\mathrm{i}} \times U_{\mathrm{i}}\right)$, where $U$ is the penultimate speed, $U_{\mathrm{i}}$ is the velocity increment, $t$ is the time swum in the final velocity increment and $t_{\mathrm{i}}$ is time interval for each increment.

Fish larvae that were swum, or siblings of the same age, were anaesthetised in chilled water, then fixed in $10 \%$ buffered formalin. After 12 to 48 h, larvae were transferred to $70 \%$ alcohol and stored. Measurements were taken of TL (from the tip of the caudal fin to the

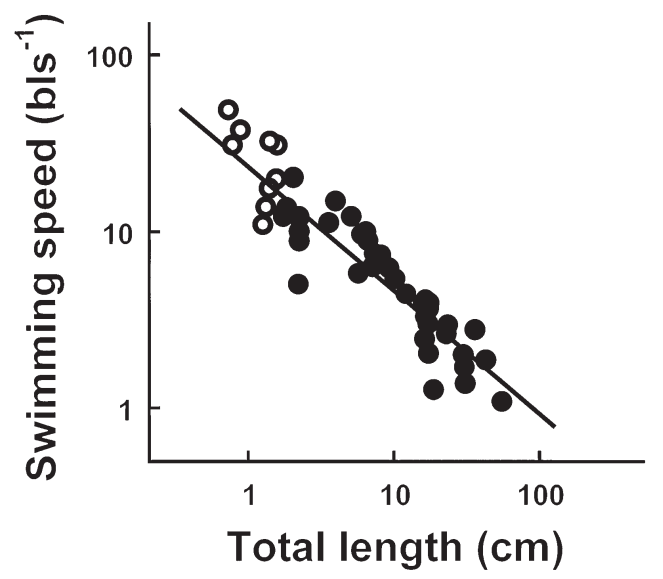

Fig. 1. Relative swimming speed versus fish body length $\left(\log _{10}\right.$ scale). Literature values (๑) and values from larvae in the present study (O). Larval values are for the fastest speeds achieved by late-stage larvae (3 batches per species). The regression line is fitted to the published values only. All swimming speeds are based on $U_{\text {crit }}$ estimates. bls ${ }^{-1}$ : body length per second tip of the upper jaw) and body depth (at the deepest point). Shrinkage of larvae due to fixation and preservation varies with age, from approximately $12 \%$ at $5 \mathrm{~mm}$ TL to $6 \%$ at $8 \mathrm{~mm}$ (Job \& Bellwood 1996). To facilitate comparisons between studies, shrinkage has not been incorporated into the estimates; however, it must be noted that this may result in a slight overestimation of relative swimming speeds, especially in small larvae. Reynolds numbers (Re) were calculated for each species at each age using the formula: $\mathrm{Re}=$ $U_{\text {crit }} \times D / v$ (after Webb \& Weihs 1986), where $U_{\text {crit }}$ is the critical swimming speed in $\mathrm{m} \mathrm{s}^{-1}, D$ is the body depth of the larvae expressed in $\mathrm{m}$ and $\mathrm{v}$ is the kinematic viscosity of seawater $\left(1.03 \times 10^{-6} \mathrm{~m}^{2} \mathrm{~s}^{-1}\right)$.

The maximum $U_{\text {crit }}$ of late stage larvae (i.e. specimens immediately before they leave the plankton to assume a benthic lifestyle) of the 3 study species were compared in a scatter plot with published values for other fish species at a range of sizes. These species included freshwater, marine, tropical and temperate fishes. $U_{\text {crit }}$ values were obtained from Brett (1967), Larimore \& Duever (1968), Jones et al. (1974), Batty (1984), Duthie (1987), Hatwell (1991), Stobutzki \& Bellwood (1994), Drucker \& Jensen (1996), Hawkins \& Quin (1996) and Peake et al. (1997). Scatter plots were also used to describe the development of critical swimming ability and changes in Re versus TL for each of the 3 species investigated.

\section{RESULTS}

In late-stage larvae, juvenile and adult fishes, relative swimming ability $\left(\mathrm{bls}^{-1}\right)$ increases exponentially with decreasing BL. Smaller individuals swim at much higher relative speeds than larger individuals (Fig. 1). The late-stage larvae examined in the present study followed the general relationship between relative swimming speed and size (Fig. 1). The high relative speeds achieved by these late-stage larvae appear to be largely a consequence of their small sizes. This size-based relationship, however, did not extend to younger, smaller larvae.

At hatching all 3 species exhibited similar swimming speeds relative to their $\mathrm{BL}$, ranging from $9.5 \mathrm{bls}^{-1}$ for Sphaeramia nematoptera to $17.0 \mathrm{bls}^{-1}$ for Pomacentrus amboinensis (Table 1). Amphiprion melanopus exhibited medium relative swimming speed (12.4 $\left.\mathrm{bls}^{-1}\right)$, even though it hatches at a considerably larger size when compared to the other 2 species (Table 1). In contrast to the general negative relationship between relative swimming speed and size in fully developed fishes, the relative swimming ability of all 3 species gradually increased with length during development. The maximum relative speed was achieved only at the 


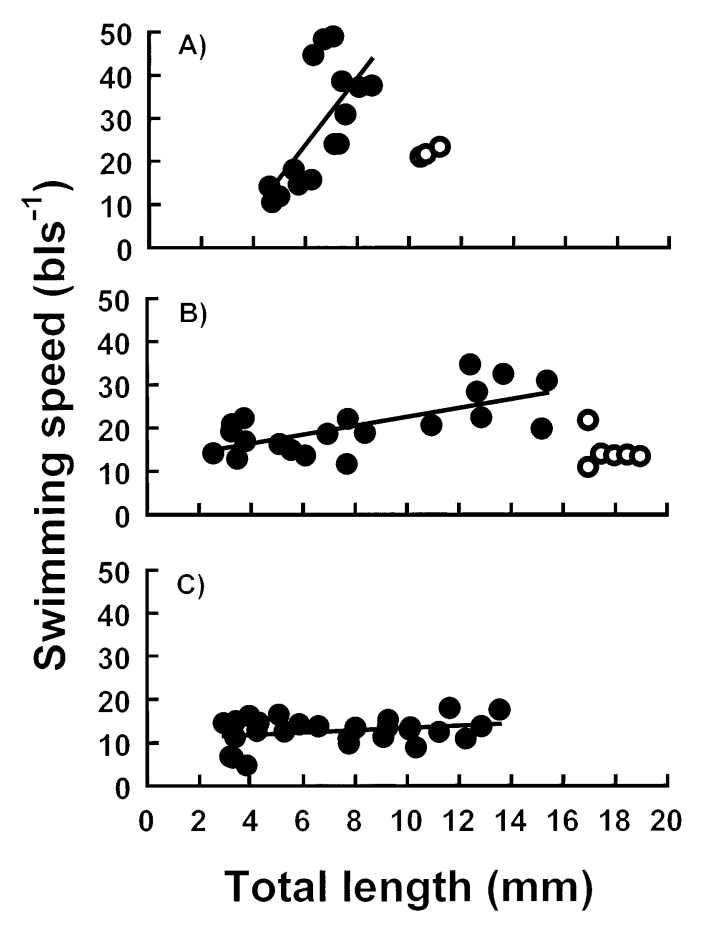

Fig. 2. Relative swimming speed of larvae versus total length for (A) Amphiprion melanopus, (B) Pomacentrus amboinensis, and (C) Sphaeramia nematoptera. (O) Post-settlement individuals (in $S$. nematoptera there is no marked metamorphosis at settlement; $P$. amboinensis values from Stobutzki \& Bellwood 1994). The regression lines are fitted to pre-settlement larvae only

end of the larval phase. This occurred at different sizes in each species (Fig. 2). A. melanopus exhibited the fastest development of relative swimming speed, attaining a maximum relative swimming speed of $49 \mathrm{bls}^{-1}$ at the end of the larval phase (cf. $34 \mathrm{bls}^{-1}$ in $P$. amboinensis and $19 \mathrm{bls}^{-1}$ in $S$. nematoptera) (Fig. 2). In both $A$. melanopus and $P$. amboinensis, relative speeds appear to decrease rapidly after settlement.

The Re also increased steadily throughout the larval period for each species, with changes reflecting the increase in absolute swimming speeds (Fig. 3). Only the smallest larvae, exhibiting slow relative swimming speeds, were swimming in a low Re regime $(<300)$. As the larvae get larger, and swim faster, they rapidly

Table 1. Mean length, $U_{\text {crit }}$ and relative swimming speed at hatching for the 3 study species. Values in parentheses represent standard errors $(\mathrm{n}=3)$. bls ${ }^{-1}$ : body lengths per second

\begin{tabular}{|lcrr|}
\hline & $\begin{array}{c}\text { Total length } \\
(\mathrm{mm})\end{array}$ & $\begin{array}{c}U_{\text {crit }} \\
\left(\mathrm{mm} \mathrm{s}^{-1}\right)\end{array}$ & $\begin{array}{c}\text { Relative speed } \\
\left(\mathrm{bls}^{-1}\right)\end{array}$ \\
\hline Amphiprion melanopus & $3.2(0.1)$ & $30(7)$ & $9.5(2.6)$ \\
Pomacentrus amboinensis & $2.9(0.5)$ & $51(3)$ & $17.0(2.5)$ \\
Sphaeramia nematoptera & $4.8(0.1)$ & $60(5)$ & $12.4(1.1)$ \\
\hline
\end{tabular}

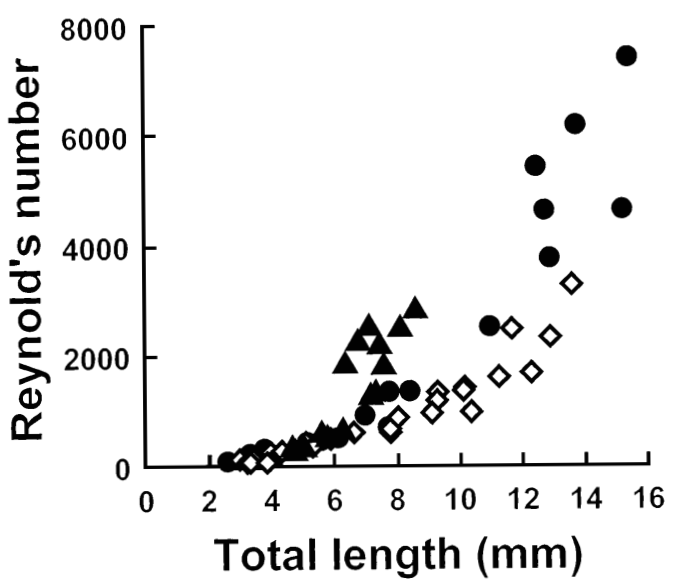

Fig. 3. Changes in Reynold's number with total length for Amphiprion melanopus $(\mathbf{\Delta})$, Pomacentrus amboinensis (•) and Sphaeramia nematoptera $(\diamond)$

leave this 'viscous' regime. The size at which larvae leave the viscous Re regime was similar in all 3 species (approximately 4 to $5 \mathrm{~mm}$ TL). The maximum relative swimming speeds of the larvae, just before settlement, are achieved in markedly different Re regimes in the 3 species. Amphiprion melanopus attained the highest relative $U_{\text {crit }}$ in a lower Re regime than the other 2 species (Figs. 2 \& 3), reflecting the high speeds achieved by Amphiprion at a small size.

Discussion. The maximum relative swimming speeds of late-stage larvae are not exceptional when compared with published values for other fish species over a range of sizes. The high relative swimming speed of late-stage larvae of coral reef fishes is largely a reflection of their small size. However, they do mark the upper limit of this size-based relationship. Smaller larvae did not display even higher swimming speeds. In all species examined, the larval period was marked by a steady increase in swimming ability with the maximum relative speed being achieved at the end of the larval phase. This occurred at different sizes in each species, suggesting that speed is dependent upon both size and developmental stage.

It has been suggested that the relative swimming speeds of smaller larvae are reduced because of the effects of viscosity when swimming at low Re values (<300) (Fuiman \& Batty 1997). Although this may constrain the abilities of small larvae, there is still a positive relationship between relative swimming speed and length, even after larvae leave the 'viscous' regime. This relationship is seen in all 3 species, even though it is exhibited in markedly different Re regimes. Indeed, the greatest relative swimming speeds were seen in Amphiprion melanopus, which achieved 
these speeds at relatively low Re values. This suggests that Re values are not critical, at least for older larvae. The observed changes in the relative swimming speeds of larvae are likely to be related to developmental constraints, with swimming performance being dependent upon the developmental schedules of the neural and musculoskeletal systems. Small larvae are capable of very high tail beat frequencies when compared to adult fish (Blaxter 1986). This may reflect key changes in the physiological basis of locomotion during development, including changes in muscle types (cf. Batty 1984, El-Fiky et al. 1987).

The achievement of maximum relative swimming speeds in late-stage larvae is consistent with the ecology of reef fishes. It is these late-stage larvae (also termed presettlement stages or late pelagic stage larvae/juveniles) that undergo the transition from the pelagic to the demersal phase of their lives. During this period there is the potential for high mortality rates and exposure to strong currents. At this stage there is likely to be strong selective pressure for well developed locomotor capabilities as the fish avoid reefbased predators whilst locating suitable settlement sites (Sancho et al. 1997). It may also be noteworthy that the highest relative swimming speeds were observed in Amphiprion malanopus, a species with a relatively short pelagic larval duration. Given this short larval duration, it is unlikely that this species would disperse far from reefs. The well developed sensory systems of larval anemonefishes (Job \& Bellwood 2000) and precocious development of swimming abilities may reflect this abbreviated period away from the reef.

Recent studies have emphasised the potential for reef fishes to maintain high rates of retention around reefs (Jones et al. 1999, Swearer et al. 1999, Cowen et al. 2000). In all cases, larval behaviour was identified as a significant contributing factor. Although several studies have highlighted the extent of intraspecific variation in swimming abilities (e.g. Leis \& CarsonEwart 1997, Stobutzki 1998) these data have provided insight into the potential performance limits of reef fish larvae. Models are now appearing that specifically incorporate key aspects of larval behaviour and swimming abilities (e.g. Armsworth 2000, Armsworth et al. in press). Our findings highlight the role of fish size with these considerations: irregardless of final abilities, relative swimming ability appears to increase up to the end of the pelagic phase and decreases thereafter following a relatively predictable pattern. Furthermore, the peak abilities approximate those values expected based simply on the size of the larvae.

Overall, maximum relative swimming speeds are strongly correlated with body size, but only in individuals with fully developed locomotor systems. In reef fishes this is probably achieved only at the end of the pelagic phase. For the majority of marine fish larvae, size is not the sole constraint on swimming speed and relative swimming speed does not increase simply as a result of decreasing size. However, the high relative maximum swimming speeds of late-stage reef fish larvae are consistent with expectations for fishes of their size. This is highlighted by the precocious development seen in anemonefishes, which results in exceptionally small late-stage larvae. Settling at 7 to $8 \mathrm{~mm}$ $\mathrm{TL}$, compared to 10 to $36 \mathrm{~mm}$ in other taxa, they are among the smallest larvae to settle on coral reefs (Leis \& Carson-Ewart 1997), and they probably represent one of the smallest fishes with fully developed locomotor capabilities. By virtue of their small size when fully developed, at 7 to $8 \mathrm{~mm}$ TL and a swimming speed of $49 \mathrm{bls}^{-1}$, late pelagic stage anemonefish larvae may mark the upper limit for sustained aquatic vertebrate locomotion.

Acknowledgements. We thank S. Job and I. Stobutzki for their invaluable advice, and J. Morrison, D. Ross and R. Rowe for technical assistance. JCU Experimentation Ethics Review Committee approvals A202, A402 and A554. This research was supported by the Australian Research Council (D.R.B.).

\section{LITERATURE CITED}

Alexander R (1982) Locomotion of animals. Blackie \& Son Limited, Glasgow

Armsworth PR (2000) Modelling the swimming response of late stage larval reef fish to different stimuli. Mar Ecol Prog Ser 195:231-247

Armsworth PR, James MK, Bode L (in press) When to press on or turn back: dispersal strategies for reef fish larvae. Am Nat

Batty RS (1984) The development of swimming movements in herring larvae (Clupea harengus). J Fish Biol 110:217-229

Blaxter JHS (1986) Development of sense organs and behaviour of teleost larvae with special reference to feeding and predator avoidance. Proc 9th Larval Fish Conf 115:98-114

Brett JR (1964) The respiratory metabolism and swimming performance of young sockeye salmon. J Fish Res Board Can 21:1183-1226

Brett JR (1967) Swimming performance of sockeye salmon (Oncorhynchus nerka) in relation to fatigue time and temperature. J Fish Res Board Can 24:1731-1741

Choat JH, Doherty PJ, Kerrigan BA, Leis JM (1993) A comparison of towed nets, purse seine and light aggregation devices for sampling larvae and pelagic juveniles of coral reef fishes. Fish Bull 91:195-209

Cowen RK, Lwiza KMM, Sponagule S, Paris CB, Olson DB (2000) Connectivity of marine populations: open or closed? Science 287:857-859

Drucker EG, Jensen JS (1996) Pectoral fin locomotion in the striped surfperch. I. Kinematic effects of swimming speed and body size. J Exp Biol 199:2235-2242

Duthie GG (1987) Observations of poor swimming performance among hatchey-reared rainbow trout, Salmo gairdneri. Environ Biol Fish 18:309-311

El-Fiky N, Hinterleitner S, Weiser W (1987) Differentiation of 
swimming muscles and gills, and the development of anaerobic power in the larvae of cyprinid fishes (Pisces, Teleosti). Zoomorphology 107:126-132

Fisher R, Bellwood DR, Job SD (2000) Development of swimming abilities in reef fish larvae. Mar Ecol Prog Ser 202: 163-173

Fuiman LA, Batty RS (1997) What a drag it is getting cold: partitioning the physical and physiological effects of temperature on fish swimming. J Exp Biol 200:1745-1755

Hatwell SI (1991) Critical swimming capacity of the Atlantic silverside, Menidia menidia L. Estuaries 14:218-221

Hawkins DK, Quin TP (1996) Critical swimming velocity and associated morphology of juvenile coastal cutthroat trout (Oncorhynchus clarkii), steelhead trout (Oncorhynchus mykiss), and their hybrids. Can J Fish Aquat Sci 53: 1487-1496

Job S, Bellwood DR (1996) Visual acuity and feeding in larval Premnas biaculeatus. J. Fish Biol 48:952-963

Job S, Bellwood DR (2000) Light sensitivity in larval fishes: implications for vertical zonation in the pelagic zone. Limnol Oceanogr 45:362-371

Jones DR, Kicenuik JW, Bamford OS (1974) Evaluation of the swimming performance of several fish species from the Mackenzie River. J Fish Res Board Can 31:1641-1647

Jones GP, Millicich MJ, Emsilie MJ, Lunow C (1999) Selfrecruitment in a coral reef fish population. Nature 402: 802-804

Larimore RW, Duever MJ (1968) Effects of temperature acclimation on the swimming ability of small-mouth bass fry. Trans Am Fish Soc 97:175-184

Leis JM, Carson-Ewart BM (1997) In situ swimming speeds of the late pelagic larvae of some Indo-Pacific coral reef fishes. Mar Ecol Prog Ser 159:165-174

Editorial responsibility: Charles Birkeland (Contributing Editor), Honolulu, Hawaii, USA
Miller TJ, Crowder LB, Rice JA, Marschall EA (1988) Larval size and recruitment mechanisms in fishes: toward a conceptual framework. Can J Fish Aquat Sci 45:1657-1670

Peake S, Barth C, McKinley RS (1997) Effect of recovery parameters on critical swimming speed of juvenile rainbow trout (Oncorhynchus mykiss). Can J Zool 75: $1724-1727$

Roberts CM (1997) Fishery and reef management. Science 279:2021-2022

Sancho G, Ma D, Lobel PS (1997) Behavioural observations of an upcurrent reef colonization event by larval surgeonfish Ctenochaetus strigosus (Acanthuridae). Mar Ecol Prog Ser 153:311-315

Stobutzki IC (1998) Interspecific variation in sustained swimming ability of late pelagic stage reef fish from two families (Pomacentridae and Chaetodontidae). Coral Reefs 17: 111-119

Stobutzki IC, Bellwood DR (1994) An analysis of the critical swimming abilities of pre- and post-settlement coral reef fishes. J Exp Mar Biol Ecol 175:275-286

Stobutzki IC, Bellwood DR (1997) Sustained swimming abilities of the late pelagic stages of coral reef fishes. Mar Ecol Prog Ser 149:35-41

Swearer SE, Caselle JE, Lea DW, Warner RR (1999) Larval retention and recruitment in an island population of a coral-reef fish. Nature 402:799-802

Webb PW, Weihs D (1986) Functional locomotor morphology of early life history stages of fishes. Trans Am Fish Soc 115: 115-127

Williams DMcB, Wolanski E, Andrews JC (1984) Transport mechanisms and their potential movement of planktonic larvae in the central region of the Great Barrier Reef. Coral Reefs 3:229-236

Submitted: June 7, 2000; Accepted: October 30, 2000 Proofs received from author(S): January 15, 2001 